grouped and given the same basal diet with added supplements. In most instances this procedure has worked satisfactorily.

In the search for the causes of the discrepancies referred to above, attention was turned to the soybean oil meal. Before the last two experiments, a new batch of the same all-vegetable diet had been mixed up, and the soybean oil meal ( $B$ in Table 1 ) in this batch was of a much better quality than that previously used. This was of an under-heated, ureaseactive type, similar to samples $A$ and $C$, the characteristics of which are given in Table 1 .

Table 1. Laboratory Characteristics of the Soybean OIL Meals. Means of triplicate determinations
Mable 1. LABORATORY CGARACTERTMS

\begin{tabular}{|c|c|c|c|}
\hline Characteristic & \multicolumn{3}{|c|}{$\underset{B}{\operatorname{Soybean}}{ }_{C}$} \\
\hline $\begin{array}{l}\text { Antiproteolytic activity (ref. } 7 \text { ) } \\
\text { Water-soluble protein, per cent of } \\
\text { total protein } \\
\text { Urease activity (ref. } 3 \text { ) : } \\
\text { (1) Time for colour change in } \\
\text { min. } \\
\text { (2) } p \text { H-change } \\
\text { Urease activity (ref. } 4 \text { ), m.equiv. } \\
\text { NH }, \text { per gm./hr. } \\
\text { Formaldehyde titration : } \\
\text { Initial } p \mathrm{H} \\
\text { mI. } 0 \cdot 1 \mathrm{~N} \text { sod. hydrox. to ad- } \\
\text { just to } p \mathrm{H} 9 \cdot 0 \\
\text { ml. } 0 \cdot 1 \mathrm{~N} \text { sod. hydrox. to } \\
\text { titrate back to } p \mathrm{H} 9 \cdot 0 \\
\text { after formaldehyde } \\
\text { Phenolphthalein test, per cent } \\
\text { transmission* }\end{array}$ & $\begin{array}{l}+++ \\
23 \cdot 8 \\
<5 \\
2 \cdot 20 \\
4 \cdot 3\end{array}$ & $\begin{array}{c}- \\
6 \cdot 3 \\
>120 \\
0 \cdot 00\end{array}$ & $\begin{array}{l}+++ \\
21 \cdot 8 \\
\\
\quad \begin{array}{r}5 \\
2 \cdot 07\end{array}\end{array}$ \\
\hline
\end{tabular}

* Variation found, approximately : underheated soybean oil meals, 21-24; optimum-heated soybean oil meals, $45-60$; overheated soybean oil meals, more than 60 .

The three samples of soybean oil meal have been studied by laboratory methods, including determination of water-soluble protein ${ }^{2}$, estimation of urease activity ${ }^{3,4}$, formaldehyde titration ${ }^{5}$, phenolphthalein adsorption test ${ }^{8}$, and estimation of antitryptic activity ${ }^{2}$. All the laboratory determinations revealed the same fact, namely, that the soybean oil meals $A$ and $C$ were under-heated and of inferior quality compared with sample $B$.

Simultaneously, a feeding experiment with these samples given as 25 per cent supplements to a basal diet was started. The results from this experiment (given in Table 2) show significantly larger gains for the chicks on the diet with soybean oil meal $B$ than on the other two samples.

\begin{tabular}{|c|c|c|c|}
\hline & \multicolumn{3}{|c|}{$A{ }_{B}^{\text {Soybean oil meal }} C$} \\
\hline $\begin{array}{l}\text { No. of chicks } \\
\text { Per cent males }\end{array}$ & $\begin{array}{l}50 \\
56\end{array}$ & 50 & 50 \\
\hline Gain, average males-females (gm.) & 181 & 207 & 180 \\
\hline $\begin{array}{l}\text { Feed consumed per kgm. gain } \\
\text { (kgm.) }\end{array}$ & $2 \cdot 53$ & $2 \cdot 38$ & $2 \cdot 52$ \\
\hline
\end{tabular}

These findings indicate that chickens fed an underheated, low-quality soybean oil meal are more rapidly depleted of their vitamin $B_{12}$-reserves, and thus have a greater need of vitamin $B_{12}$ in the diet. Whether this is due to the antiproteolytic activity or the content of soyin (a thermolabile toxic protein, recently discovered by Liener and Pallansch ${ }^{8}$ ) in the lowquality meal is not clear. It seems probable, however, that the antiproteolytic activity, with the resulting decreased availability of essential amino-acids ${ }^{9}$, does play an important part in the chicken's requirements of vitamin $B_{12}$. In addition, the calcium - iron ratio and the vitamin $\mathrm{D}$ content of the diet must be reevaluated when using low-quality soybean oil meal.

It is intended to investigate these interrelationships in further experiments.

National Animal Experiment Station,

Allan Frölich

$$
\begin{gathered}
\text { Uppsala. } \\
\text { Oct. } 6 .
\end{gathered}
$$

${ }^{1}$ Rubin, M., and Bird, H. R., Poultry Sci., 25, 526 (1946).

${ }^{2}$ Smith, A. K., and Circle, S. J., Indust. Eng. Chem., 30, 1414 (1938).

${ }^{3}$ Caskey, C. D., and Knapp, F., Indust. Eng. Chem. (Anal. Edit.), 16, $640(1944)$

4 Arnold, L. K. (unpublished), cited by Balloun, S. L., Johnson, E. L. and Arnold, L. K., Poultry Sci., 32, 517 (1953).

${ }^{5}$ Almquist, H. J., and Maurer, S., Poultry Sei., 32, 549 (1953).

"Frölich, A. (to be published).

'Westfall, W. J., and Hauge, S. M., J. Nutr., 35, 379 (1948).

${ }^{8}$ Liener, I. E., and Pallansch, M. J., J. Biol. Chem., 197, 29 (1952).

-Almquist, H. J., and Merritt, J. B., Arch. Biochem. Biophys., 31, 450 (1951); 35, 352 (1952).

\section{Polygametic Zygotes as a Source of Polyploidy and Irregular Ratios in Yeast}

Roman, Hawthorne and Douglas ${ }^{\mathbf{1}}$, on the basis of analysis of an ascus, suggested that irregular ratios in yeast may result from polyploidy. Lindegren and Lindegren ${ }^{2}$ endorsed the idea on finding another exceptional ascus.

A source of polyploidy in yeast came to light while one of us (M. A.) was examining a cross between two

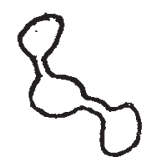

Fig. 1. A zygote of thre $\times 750$ formed by the union single-spore cultures from a local strain of Saccharomyces carlsbergensis Hansen. A zygote, which was formed by the union of three gametes, was observed (Fig. 1). On further search, one more trigametic zygote was found. Both these zygotes were isolated by means of the micro-manipulator but they failed to give viable colonies.

No polygametic zygotes have been observed in yeast before, but there are a few records in Angiosperms where more than two gametes have probably taken part in the formation of an embryo ${ }^{3}$.

The trigametic zygotes observed by us in yeast. clearly suggest that they can be a source of triploid cells in crosses. Likewise, tetragametic zygotes will be a source of tetraploid cells. Roman et al. and Lindegren and Lindegren analysed asei from mass matings, and found asei organized presumably by tetraploid cells which may have come from tetragametic zygotes. The fact that we have so far not. found tetraploid asci seems to be due to the fact that we isolate digametic zygotes and analyse progeny from such zygotes only.

The observation of trigametic zygotes shows that polygametic zygotes may be formed during mass matings of yeast. Such zygotes will give rise to polyploid cells which in turn will show polysomic inheritance and exhibit departures from $2: 2$ segregations.

\section{Majeed Ammad}

Department of Botany,

\section{AzeEz KHAN}

University of Dacca,

Pakistan.

Sept. 10.

${ }^{1}$ Roman, H., Hawthorne, D. C., and Douglas, H. C., Proc. U.S. Nat. Acad. Sci., 37, 79 (1951).

${ }^{2}$ Lindegren, C. C., and Lindegren, G., J. Gen. Microbiol., 5, 885 (1951). ${ }^{3}$ Ishikawa, M., Ann. Bot., 32,279 (1918). Michaelis, P., and Delling-
hausen, M. V., Jenaische Z. Vererb., 80, 373 (1942). 